\title{
СУЩНОСТЬ МЕЖДИСЦИПЛИНАРНОГО ВЗАИМОДЕЙСТВИЯ ПРИ РАЗВИТИИ ТЕРРИТОРИЙ В УСЛОВИЯХ ЦИФРОВОЙ ЭКОНОМИКИ
}

\section{THE ESSENCE OF INTERDISCIPLINARY INTERACTION IN THE DEVELOPMENT OF TERRITORIES IN THE DIGITAL ECONOMY}

T. Ablyazov

Summary. In the digital economy, the implementation of territorial development projects reaches a qualitatively new level associated with the widespread dissemination of digital technologies in the framework of modern concepts of improving the comfort of the living environment. The article considers the essence of interdisciplinary interaction in the development of territories and analyzes the evolution stages of this concept. As a result of the work, the peculiarities inherent in the interdisciplinary approach at different stages of its formation were identified and the ways of further development of this type of interaction during the implementation of projects to improve the comfort of human life were proposed.

Keywords: interdisciplinary interaction, territorial development, digital economy, increasing the comfort of the living environment, "smart" city.
B условиях становления цифровой экономики как за рубежом, так и в России вопросы развития территорий на основе распространения современных технологий приобретают первостепенную значимость для специалистов разных областей знаний. Цифровая экономика представляет собой систему социально-экономических отношений, в которой взаимодействие субъектов и объектов основано на обмене цифровыми данными посредством информационно-коммуникационных технологий [1]. Одним из направлений развития территорий с использованием элементов цифровой экономики является концепция «умного города», в рамках которой предполагается совершенствование транспортной и инженерной инфраструктур, внедрение практики энергосбережения, повышение доступности государственных услуг для населения и бизнеса, причем достижение различных плановых показателей эффективности проводимых мероприятий связано с внедрением тех или иных цифровых платформ и технологий [2].
Аблязов Тимур Хасанович

К.э.н., Санкт-Петербургский государственный архитектурно-строительный университет 3234969@mail.ru

Аннотация. В условиях цифровой экономики реализация проектов развития территорий выходит на качественно новый уровень, связанный с широким распространением цифровых технологий в рамках современных концепций по повышению комфортности среды жизни. В статье рассмотрена сущность междисциплинарного взаимодействия при развитии территорий и проанализированы этапы эволюции данного понятия. В результате работы были выявлены особенности, присущие междисциплинарному подходу на разных этапах его становления, и предложены пути дальнейшего развития данного вида взаимодействия при реализации проектов по повышению комфортности среды жизни человека.

Ключевые слова: междисциплинарное взаимодействие, развитие территорий, цифровая экономика, повышение комфортности среды жизни, «умный» город».

Усложнение и ускорение процессов развития территорий в условиях цифровой экономики привело к необходимости выработки комплексных решений на основе теории и практики различных технических, естественных, общественных и гуманитарных наук. Именно междисциплинарный подход является ключевым фактором, способствующим формированию комфортной среды жизни человека, так как только при взаимодействии множества специалистов из разных областей науки становится возможной выработка единой, максимально удовлетворяющей потребности всех экономических субъектов, стратегии развития территории.

В наиболее общем смысле при междисциплинарном подходе для решения задачи одной дисциплины применяется методология другой дисциплины, тем самым обнаруживаются общие предметные области [3]. Однако современные условия цифровой трансформации всех сфер жизнедеятельности человека диктуют новые тре-

1 Статья подготовлена в рамках работы по гранту Президента Российской Федерации МК-462.2020.6. 
бования к междисциплинарному взаимодействию, что требует более глубокого рассмотрения сущности данного понятия.

В целом среда жизни человека в настоящее время рассматривается с точки зрения четырех уровней [4]. Первый уровень - функциональный, описывающий суть работы тех или иных систем и инфраструктур. На втором уровне внимание уделяется безопасности среды жизни в условиях функционирования различных систем, в частности, цифровых. На следующем, третьем, уровне анализа находятся интеллектуальные системы, являющиеся неотъемлемой частью современных концепций комфортной среды жизни таких как, например, «умный город». На последнем уровне рассматриваются виды и способы непосредственного внедрения технологий в среду жизни человека, «архитектура» принимаемых технических решений. Все вышеперечисленные уровни анализа связаны с различными областями знаний, и поэтому применение междисциплинарного подхода является основным элементом успешного решения задач по комплексному совершенствованию среды жизни в условиях становления концепции цифровой экономики.

Развитие среды жизни человека предполагает аккумуляцию теории и практики общественных, естественнонаучных, прикладных и инженерных наук, что в совокупности позволит обеспечить устойчивость функционирования различных инфраструктур [5]. Результатом распространения междисциплинарного подхода при решении задач в области формирования комфортной среды жизни стало появление новых наук. В начале 21 века получила начало такая дисциплина как наука об устойчивом развитии, в рамках которой поставлена цель интегрального познания системы жизнедеятельности планеты и населения на основе междисциплинарного взаимодействия между экономистами, социологами и учеными естественнонаучных направлений $[6,7,8]$.

Объединение городского планирования, ландшафтной архитектуры и гражданского строительства привело к выработке такой области знаний как градостроительный дизайн [9], в рамках которого решаются вопросы комплексного проектирования агломераций с учетом потребности населения в определенных услугах и системах. Более того, внедрение цифровых технологий в среду жизни человека привело к появлению таких междисциплинарных наук как городские информационно-коммуникационные технологии (urban ICT) и теория городских вычислений (urban computing) [10]. В рамках данных междисциплинарных наук на основе объединения информационных технологий, программной инженерии, градостроительного, транспортного и экологического проектирования, экономики и социо- логии изучается взаимовлияние цифровых технологий и процессов функционирования территории [11].

Тем не менее междисциплинарный подход не ограничивается появлением новых дисциплин на стыке областей знаний. Выделяют следующие понятия, отражающие сущность взаимодействия различных специалистов в рамках реализации проектов по формированию комфортной среды жизни человека:

1. Мультидисциплинарное взаимодействие, при котором для решения проблемы применяется методология, принятая в каждой из дисциплин, то есть сохраняются дисциплинарные подходы [12];

2. Междисциплинарное взаимодействие, подразумевающее обмен знаниями специалистов разных областей для решения общей задачи [13];

3. Трансдисциплинарное взаимодействие, при котором новые знания генерируются уже за пределами существующих областей, образуя новые дисциплины [14].

Важная роль междисциплинарного подхода при реализации проектов развития территорий была признана еще в первой половине 20 века: предполагалось сотрудничество профессионалов, властей и населения; территории должны были рассматриваться не как отдельные города, а как системы городов и области, которые они образуют [15]. Первоначально развитие получил мультидисциплинарный подход, который постепенно к началу 21 века трансформировался в междисциплинарный, при котором задачи по формированию комфортной среды жизни человека решаются командой специалистов из смежных областей $[16,17]$. Однако в условиях усложнения системы функционирования территорий в связи с ростом значимости экологических, политических и общественных факторов, таких как демократизация и распространение практики участия населения В принятии решений по развитию территорий, междисциплинарный подход сталкивается со сложностями в обработке значительного количества разрозненных данных и в выработке с учетом всех факторов влияния оптимальных решений по повышению комфортности проживания на территории. В результате, междисциплинарное взаимодействие зачастую превращается в попытку учесть всю информацию, хотя не всегда данные подлежат сравнению друг с другом, что приводит к разработке множества стратегий, проектов долгосрочного развития и генеральных планов, которые реализуются на минимальном уровне в связи со своей обособленностью от реальных условий функционирования территории $[18,19]$.

Стоит отметить, что взаимодействие специалистов разных областей для решения общей задачи на меж- 
дисциплинарном уровне требует разработки доступных для всех участников понятийного аппарата, методов обработки данных, а также подразумевает установление совместимости систем, используемых разными специалистами в своей работе [20]. В настоящее время в качестве следующего этапа развития междисциплинарного подхода при формировании комфортной среды жизни предполагается распространение практики трансдисциплинарного взаимодействия, особенностью которого является создание новых знаний на стыке существующих областей науки. Так, модель И.М. Смоляра [21] подразумевает установление сотрудничества между специалистами 18 направлений, из таких областей как городское управление, право, землеустройство и кадастр, архитектура, климатология, экология, социология, экономика, демография и некоторые другие, что в совокупности создаст более 150 возможных сочетаний для генерации качественно новых знаний. Еще одна модель междисциплинарного взаимодействия при реализации проектов развития территорий отражает многоаспектность и сложность данного процесса, и в качестве ключевых областей знаний в ней выделяются теория пространственной организации, городская экономика и правовое регулирование градостроительства [22].

В целом, процесс развития междисциплинарного взаимодействия в рамках формирования комфортной среды жизни привел к постепенному переходу к инте- гральным показателям, отражающим комплексные параметры, как например, уровень привлекательности территории, качество общественных связей, мобильность населения [23].

Тем не менее сущность данного понятия неоднозначна, так как междисциплинарное взаимодействие находится в процессе постоянной эволюции, постепенно приобретая черты трансдисциплинарности, что уже сегодня нашло отражение в появлении новых дисциплин, связывающих цифровые технологии с экономикой, социологией, градостроительным проектированием и инженерными науками.

В заключение стоит сказать, что под развитием территорий в условиях цифровой экономики в настоящее время понимается повышение комфортности и безопасности среды жизни человека на основе внедрения цифровых технологий. Однако различные структуры, обеспечивающие процессы жизнедеятельности на территории, зачастую имеют собственные методики сбора, анализа и представления информации. Именно применение междисциплинарного подхода позволит наиболее эффективно реализовывать проекты по формированию комфортной среды жизни за счет повышения степени взаимодействия специалистов разных специальностей при решении общей задачи - развитие территории на основе элементов цифровой экономики.

\section{ЛИТЕРАТУРА}

1. Ablyazov T., Asaul V. On competitive potential of organization under conditions of new industrial base formation // SHS Web of Conferences, vol. 44, $00003,2018$. URL: https://www.shs-conferences.org/articles/shsconf/pdf/2018/05/shsconf_cc-tesc2018_00003.pdf (дата 0бращения: 26.05.2020).

2. Vishnivetskaya A., Alexandrova E. «Smart city» concept. Implementation practice // IOP Conference Series: Materials Science and Engineering. vol. 497, 012019, 2019. URL: https://iopscience.iop.org/article/10.1088/1757-899X/497/1/012019/pdf (дата обращения: 27.05.2020).

3. Мокий В.С., Лукьянова Т. А. Междисциплинарные взаимодействия в современной науке: подходы и перспективы // Экономическая наука современной России. 2017. № 3 (78). С. 7-21.

4. Ristvej J., Lacinák M., Ondrejka R. On Smart City and Safe City Concepts // Mobile Networks and Applications, 2020. URL: https://doi.org/10.1007/s11036-02001524-4 (дата обращения: 23.05.2020).

5. Bibri S.E., Krogstie J. Smart sustainable cities of the future: An extensive interdisciplinary literature review // Sustainable Cities and Society, vol. 31, 2017, p. 183212. URL: https://doi.org/10.1016/j.scs.2017.02.016 (дата обращения: 23.05.2020).

6. Clark W.C., Dickson, N. M. Sustainability science: The emerging research program // Proceedings of the National Academy of Science USA, vol. 100, № 14, 2003, p. 8059-8061. URL: https://doi.org/10.1073/pnas.1231333100 (дата обращения: 24.05.2020).

7. Kates R., ClarkW., Corell R., Hall J., JaegerC. Sustainability science//Science, vol. 292, № 5517, 2001, p. 641-642. URL: https://www.jstor.org/stable/3083523?seq=1 (дата обращения: 15.04.2020).

8. Clark W. C. Sustainability science: A room of its own // Proceedings of the National Academy of Science, vol. 104, № 6, 2007, p. 1737-1738. URL: https://doi. org/10.1073/pnas.0611291104 (дата обращения: 15.05.2020).

9. Van Assche K., Beunen R., Duineveld M., de Jong H. Co-evolutions of planning and design: Risks and benefits of design perspectives in planning systems // Planning Theory, vol. 12, № 2, 2012, p. 177-198. D0l: 10.1177/1473095212456771

10. Paulos E., Goodman E. The familiar stranger: anxiety, comfort, and play in public places // Proceedings of the SIGCHI Conference on Human Factors in Computing Systems, vol. 6, № 1, 2004, p. 223-230. URL: https://dl.acm.org/doi/pdf/10.1145/985692.985721 (дата обращения: 21.04.2020).

11. Zheng Y., Capra L., Wolfson 0., Yang H. Urban computing: Concepts, methodologies, and applications // ACM Transactions on Intelligent Systems and Technology, vol. 5, № 3, 2014, p. 1-55. URL: https://doi.org/10.1145/2629592 (дата обращения: 11.04.2020).

12. Frodeman R., Klein J. Mitcham C. The Oxford Handbook of Interdisciplinarity. Oxford: Oxford University Press, 2010. — $580 \mathrm{p}$. 
13. Park J-Y., Son J-B. Transitioning toward transdisciplinary learning in a multidisciplinary environment // International Journal of Pedagogies and Learning, vol. 6, № 1 , 2010, p. 82-93. URL: https://doi.org/10.5172/ijpl.6.1.82 (дата обращения: 02.05.2020).

14. Marinova D., McGrath N. A transdisciplinary approach to teaching and learning sustainability: A pedagogy for life, Teaching and Learning Forum // Proceedings of the 13th Annual Teaching Learning Forum, 2004. URL: http://lsn.curtin.edu.au/tlf/tlf2004/marinova.html (дата обращения: 05.05.2020).

15. Хан-Магомедов С. О. Архитектура советского авангарда. Книга 2. Социальные проблемы.— М.: Стройиздат, 2001.— 712 с.

16. Després C., Vachon G., Fortin A. Implementing Transdisciplinarity: Architecture and Urban Planning At Work // Urban and Landscape Perspectives, vol. 11, 2011, p. 33-49. URL: https://link.springer.com/chapter/10.1007/978-94-007-0104-5_3 (дата обращения:06.04.2020).

17. Pinson D. Urban Planning: An «Undisciplined» Discipline? // Futures, vol 36, № 4, р. 503-513. URL: https://doi.org/10.1016/j.futures.2003.10.008 (дата 06ращения: 10.04.2020).

18. Лаврик Г.И., Реутов 0. И., Щербакова Т. Н. Подготовка научных кадров — кардинальная проблема градостроительства настоящего и будущего // Градостроительство. 2013. № 6 (28). С. 36-41.

19. Бочаров Ю.П., Жеблиенок Н. Н., Жеблиенок М. А. Трансдисциплинарность как направление развития современного градостроительства // Асаdетіа. Архитектура и строительство. 2018. № 4. С. 66-73.

20. Eslami-Andargoli A., Bernus P., Kandjani H. Analysis of Interoperability Issues in Queensland Disaster Management System // Proceedings of 15th International Conference on Enterprise Information Systems (ICEIS), 2013. URL: https://www.researchgate.net/publication/266970793_Analysis_of_Interoperability_Issues_ in_Queensland_Disaster_Management_System (дата обращения: 15.05.2020).

21. Белоусов В.Н., Сдобнов Ю. А., Смоляр И. М. Основы комплексной междисциплинарной научной программы «Теория города».— М.: PAАСН, 2004 (000 Р0$X O C) .-56 C$.

22. Высоковский А.А. 0 Высшей школе урбанистики // Проект Россия. Журнал о «Сколково» и городской среде. Март 2012. С. 36-38.

23. Loupa Ramos l., Ferreiro M., Colaco C., Santo S. Peri-urban landscapes in metropolitan areas: using transdisciplinary research to move towards an improved conceptual and geographical understanding // Proceeding of the AESOP-ACSP joint congress, 2013. https://www.researchgate.net/publication/303541342 (дата обращения: 25.05.2020).

(c) Аблязов Тимур Хасанович ( 3234969@mail.ru)

Журнал «Современная наука: актуальные проблемы теории и практики»

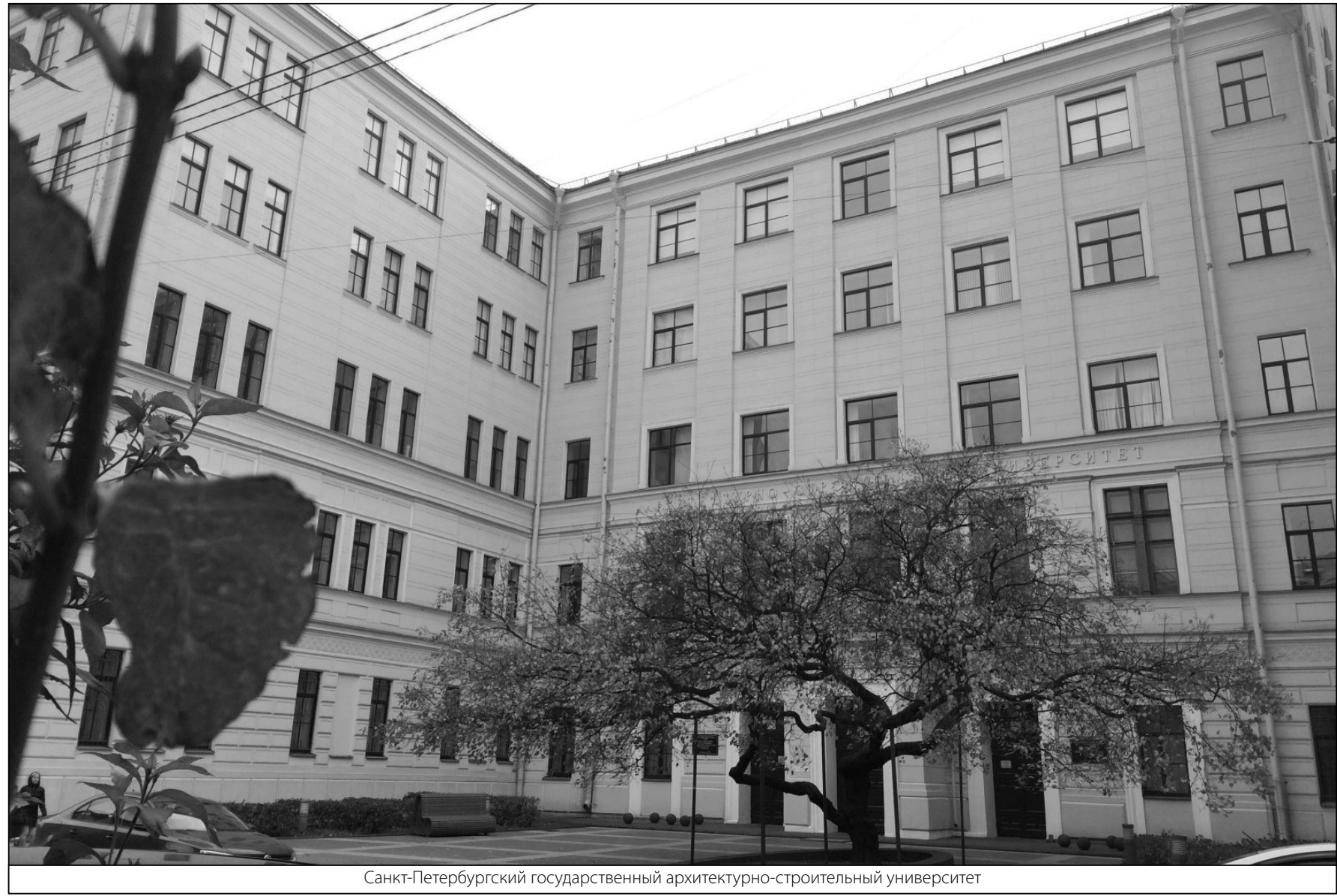

